\title{
Virgin Coconut and Fish Oil (VCFO) For Treatment of Fungal Cat Infection in Malang
}

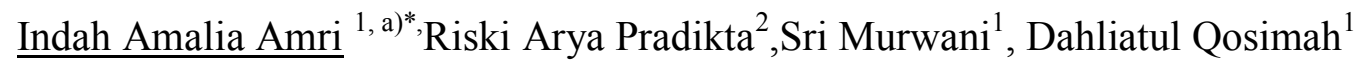 \\ ${ }^{1}$ Faculty of Veterinary Medicine, University Brawijaya, Malang \\ ${ }^{2}$ DVM of Buchi Pet Shop, Malang ${ }^{a)}$ Corresponding author: indahamaliaamri@ gmail.com
}

\begin{abstract}
The increased people's lives and the need for entertainment make the existence of pets getting noticed and interesting. Among the various species of pet, cat is most popular in Indonesia. The high rate of cat lovers in Malang at this time was not followed by their knowledge about the how to maintain a cat. According to available data in the Buchi Pet Vet Shop 2014, cases of the disease that is the place indicates that the fungal infection is still the highest at around 20-30 cases per month, it is the underlying to conduct community service activities in Buchi Pet Shop. Clinical symptoms of fungal infections are hair loss and the appearance of the crust. Medications that often used include to be given ketoconazole, miconazole, or griseofulvin, but the giving these medicines can cause dangerous side effects when given the intensity for long time. Due to the side effects of these harmful then the need for additional drugs that can be supportive therapy in the treatment of fungal infections. One is through the use of VCO and fish oil (VCFO). According to research from VCO can function as anti-fungal and fish oil can accelerate the growth of hair. Events Community Services held on April 4, 2016 in Buchi Pet Shop was attended by 35 participants, the event is a fungal disease counseling, pet animal management and the benefits of utility VCFO, demonstrations on the use of oral VCFO, and the third session is vaccination of cats. Based on the results of the evaluation VCFO gives good results for the treatment of fungal infections and therapy orally accelerate regeneration or new hair growth and based on the results of questionnaires and discussion of current events concluded that the activities community service this goes well and get a positive response from among the lovers of pets, more people can know the benefits VCFO as an alternative for the treatment of fungal infections in cats.
\end{abstract}

Keywords:VCFO, Fungi, Herbal

\section{INTRODUCTION}

Today people need a means to deliver a hobby, pleasure and affection, one way to keep a pet. With increasing number of people in Indonesia at this time the number of people who raised even more and more, one of them in the city of Malang. Increasing the number of population in the city of Malang cat owners is growing every year. But it is not followed by the high public knowledge about how they maintain their animals well.

The emergence of diseases ranging from infection by viruses, bacteria, parasites and fungi are just infectious among cats to be transmissible to humans (zoonoses) is still a major concern for cat owners. Fungal infection is one of the diseases in cats that are included in the category of frequently occurred in the city of Malang.

The purpose of this community service activity is to provide knowledge for the pet lovers in Malang on fungal infections in cats that do prevention and appropriate treatment.

The target audience of community service is the cat lovers in Blimbing district which is the center of an area with a population of pet that much and still need coaching and guidance from educators and government agencies.

The method of implementation is education through the transfer of knowledge to the public, by way of extension of a fungal disease in cats as well as training and demo use VCFO (virgin 
coconut oil and fish oil) as an herbal remedy for topical fungal diseases

\section{METHODS}

\section{Counseling and Discussion}

Fungal diseases which include agents causes, transmission, clinical symptoms, treatment and how to control it and the output understands of cat owners perform an analysis of fungal diseases in cats and how to control it.

\section{Demoplot}

Do a demo practice for topical administration VCFO in cats exposed to the fungus.

\section{Evaluation}

Evaluation or feedback sheet the form of multiple questions about extension activities and training provided by the Community Service Team in the form of ratings of satisfaction with the activity; satisfied, less satisfied and not satisfied and the short answer is that it can be used as an indicator to see how far the value of the benefits of such devotion.

\section{RESULTS}

Events Community Services held on April 4, 2016 in Buchi and Vet Pet Shop, Street Sebuku No. 11 Malang. The event is divided into three sessions: the first session filled with education about fungal diseases, pet animal management and the benefits of usability VCFO, the second session is a demonstration of the use VCFO topically and orally, and the third session is vaccination of cats and dog.

The event was attended by 35 participants from Malang animal pet lovers and students of UB Faculty of Veterinary Medicine. Based on the results of questionnaires filled out by the participants, as $90 \%$ or 32 participants had a pet cat with a number ranging from 1 to 3 , while $10 \%$ or 3 participants have pet dogs.

At the first session is education about the management of pet animal associated with fungal infections in cats, it can be concluded that the majority of participants are less know how to care for pets properly and right, both in terms of management of feed, the majority of participants leave cat food with protein levels were low, but protein is so necessary to maintain and build body tissues, and in terms of management of cleanliness cat, participants rarely do grooming except their dogs 
and cats exposed disease infestation and fungus, based on questionnaire data obtained the majority of pet owners already do vaccinate their animals, but the owner of the animal $90 \%$ did not revaccine, some diseases also infect cats and dogs, this is gastrointestinal disease that is characterized by clinical symptoms of diarrhea ranks the first one, followed by skin diseases, one of which is a fungus. Handling of fungal diseases can be done by giving antifungal, among others ketocenazole and do grooming, but because animals cats and dogs have a habit licked the body, it is very likely ointment can be ingested by animals, while it is known that ketocenazole have hepatotoxic side effects, so it is necessary to product antifungal safe and does not cause side effects that come from nature, one of which is VCO.

Description on the label VCFO are: VCFO a combination of coconut oil and fish oil are rich in nutrients for skin health of your pet. VCFO also be efficacious to treat itching due to fungal infection, attack fleas, mites and ticks. In addition VCFO can also be used to increase endurance your pet. Rules: 1) Pour the VCFO to just enough the cotton and then apply on skin infections / itchy and allow it to sink in, use $2 \mathrm{x}$ daily, 2) by oral; enter slowly into the mouth with a spoon / syringe, dose: cats / small dogs: $2 \times 1(0,5 \mathrm{ml})$, cat / dog large: $2 \times 1(1 \mathrm{ml})$.

In this community service activities, in Buchi Petshop and Vet are hospitalized patients 2 years old male cat with gray fur color, suffering from yeast infections in the head and neck, the head and neck feathers shaved and was given treatment include: shower fungus, ointments ketocenazole for 1 week and continued with the VCFO topically and orally, after two weeks there is a significant change in the cat's head had started to grow the feathers replace hair loss due to fungal infection, and also increases appetite cat, cat fur also looks shiny, this is due to the omega 3 VCFO are very good for the health of fur and skin a cat.

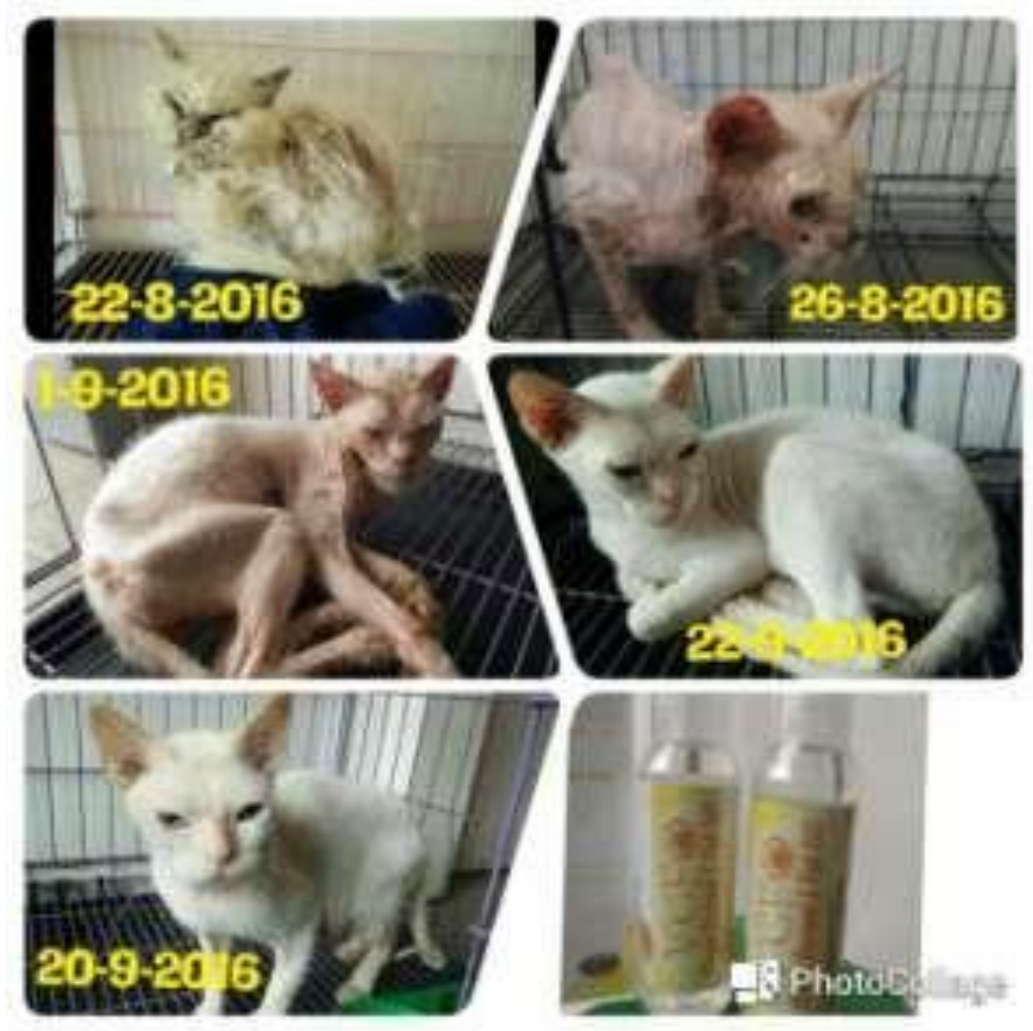

